\title{
'Defeating the dragon' - can we afford not to treat patients with heroin dependence?
}

A worrying increase in heroin use disorders has been noted in South Africa over recent years. Despite this, very limited treatment options exist in the state sector. This article provides a brief overview of the local extent of the problem and its implications, and discusses treatment options. It briefly investigates international treatment implementation strategies and makes suggestions for local policy.

Opioid dependence is a remarkably persistent, often lifelong disease. It is a biological disorder, with genetic underpinnings and complex environmental and individual determinants, associated with characteristic neurological abnormalities and related behavioural changes. It should therefore be considered a medical disorder, best treated via a medical intervention model.'

South Africa is situated along one of the primary drug trafficking routes through Africa, and recent increases in the production of opium with subsequent record levels of supply from Afghanistan have led to the availability of cheap, reasonably good-quality heroin (about R30 per 'quart'/'bag'/'beat'/quarter of a gram in Cape Town). ${ }^{2}$ Heroin use has gradually increased in South Africa, and according to trend statistics from the South African Community Epidemiology Network on Drug Use (SACENDU) surveillance project it is the illicit opioid of choice among local users. $^{3}$ There is limited research that accurately estimates the true extent of our heroin problem. A study by Plüddemann et al. in 2003/4 estimated that there were between 12000 and 18000 heroin users in Cape Town. ${ }^{4}$ The heroin problem is still largely contained, but there have been recent worrying reports of pockets of endemic use in the greater Cape Town area, where the number of patients with heroin use disorders equalled or even overtook the number of patients with methamphetamine use disorders in some treatment programmes. Similarly, there has been great concern over the rapid increase in KwaZulu-Natal of patients presenting for substance treatment who report heroin as their primary drug of choice, the proportion having increased from about $2 \%$ in 2006 to $30 \%$ in 2009 . The figure rises to $34 \%$ in the $<20$-year age group. This increase is largely due to the use of 'sugars', a mixture of mainly heroin and cocaine. ${ }^{3}$

Heroin use is associated with major health risks. These include dependence and withdrawal; fatal and non-fatal (mostly accidental) overdoses, which are often associated with permanent neurological and neurocognitive deficits; problems associated with injection use, including blood-borne virus transmission; problems due to associated high rates of polydrug use; and increased rates of other health problems such as tuberculosis and pneumonia.

The World Drug Report warns that new epidemics of HIV infection in sub-Saharan Africa are occurring as a result of intravenous drug use. ${ }^{2}$ In South Africa injection drug use is particularly high in Gauteng, with $31 \%$ of patients in treatment reporting regular intravenous use. This increases to $51 \%$ if only white males in this area are considered. ${ }^{4}$ Plüddemann et al. found that $89 \%$ of injection heroin users in their study had shared needles with other addicts and nearly half had been denied needles by pharmacies, where they are generally purchased. ${ }^{5}$

Heroin use disorders are also associated with high levels of psychopathology. Studies looking at psychiatric co-morbidity among heroin treatment seekers have estimated rates as high as $80 \%$, with mood disorders, anxiely disorders (including posttraumatic stress disorder), and personality disorders (especially anti-social and borderline personality disorders) being the most prevalent.

Compared with other drugs used in South Africa, heroin is less of a male phenomenon, raising concerns about neonatal effects (such as neonatal abstinence syndrome in babies of addicted mothers) and concerns over parenting abilities of these mothers, all of which add to the burden of heroin dependence on society. ${ }^{3}$

Mortality among heroin users is shockingly high, being estimated at about $1-4 \%$ per annum, or 13 times that of their peers. ${ }^{7}$ This increased mortality is mainly due to overdoses, violence, suicide, HIV infection and other substance use-related problems. There are no accurate statistics available on heroin death rates in South Africa, but Plüddemann et al. found that half of their study participants had heard of a heroin overdose death in the previous year. ${ }^{5}$

Heroin dependence places a significant burden on the economy. It directly impacts on health care costs and social welfare and 
criminal justice budgets, and reduces productivity through unemployment, absenteeism and early death. ${ }^{8}$ It is therefore important that policymakers and treatment providers take note of this rise in heroin use disorders and that the country considers its options and prepares for a potential crisis.

\section{Aims of treatment}

The ideal treatment outcome for opioid dependence is cessation of opioid use, along with optimal health and social functioning. However, both international and local evidence suggests that only a minority of opioid-dependent patients are able to achieve total abstinence in the short term. The National Treatment Outcome Research Study found that $34 \%$ of the patients relapsed to heroin use within 3 days, $45 \%$ within 7 days, $50 \%$ within 14 days, and $60 \%$ within 90 days. ${ }^{9}$ Similarly, an unpublished study performed at the Opioid Detoxification Unit at Stikland Hospital, Cape Town, where case notes of 356 patients admitted between June 2007 and June 2008 were reviewed, found the mean period of maximum sobriety following previous treatment episodes was 9 days. When asked about the duration of sobriety after their last treatment episode, as many as 30\% reported that they relapsed immediately; $41 \%$ relapsed within one week, $54 \%$ by one month, $69 \%$ by 3 months and $93 \%$ by one year.

Many patients, however, do eventually achieve remission from addiction to illicit opioids, ${ }^{10}$ and most experts therefore agree that treatment should aim to reduce/cease illicit opioid use, prevent harms associated with opioid use to the individual and the community, and improve the quality of life and well-being of the patient. ${ }^{8}$

\section{Treatment options}

Treatments can be broadly divided into two approaches, namely those based on opioid withdrawal and relapse prevention and those based on opioid substitution treatment (OST), the latter sometimes being referred to as opioid replacement or opioid maintenance treatment. As no single treatment is effective in all cases, outcomes are improved by providing sufficiently diverse treatment options. ${ }^{8}$

\section{Opioid withdrawal ('detoxification') and relapse prevention}

This is the most widely used treatment approach in South Africa, but high relapse rates indicate that it is remarkably ineffective." Naltrexone, an opioid antagonist, can be used to improve post-detoxification outcomes. It is available abroad in tablet form, as an extended-release depot injection and as a slowrelease implant. Compliance problems with the oral formulation have been found to limit its usefulness, and extended-release formulations are extremely expensive. ${ }^{12}$ Naltrexone is not registered in South Africa.

Total abstinence is achievable by a significant minority of patients and should always be available as a treatment option if the patient prefers this, especially for a young patient, whose illness has not yet become entrenched.

\section{Opioid substitution treatment (OST)}

OST consists of the medically supervised daily consumption of an individualised dose of long-acting oral or sublingual opioid agonist or partial agonist; this is a substitute for the illicit usually smoked or injected opioid, thereby preventing withdrawal symptoms and cravings. The resulting stable opioid effect is experienced by the user not as intoxication or a 'high', but rather as being 'normal'. This allows patients to stabilise their lifestyle, rebuild relationships, find employment, move away from the drug subculture and stop drug-seeking behaviour.

In practice, most patients on OST will stop using heroin or only use it infrequently. Only about $20-30 \%$ practise ongoing regular heroin use. ${ }^{10}$ Opioid substitution is internationally recognised as a safe and effective treatment for opioid dependence. It is supported by a large body of research literature and clinical practice. ${ }^{13}$ It has been shown to decrease illicit opiate use and to reduce the incidence of high-risk and unlawful behaviours associated with opioid dependence. ${ }^{14-16}$ Effects include reduced morbidity $^{17}$ (including HIV risk, ${ }^{18}$ incarceration $^{19}$ and other substance use ${ }^{20}$, reduced mortality ${ }^{21}$ associated with heroin dependence, and improved treatment retention. Compared with detoxification and psychosocial interventions, OST has been shown to produce better outcomes. ${ }^{22}$ Furthermore, OST increases legitimate earnings, employment and other indicators of improved social functioning. It is therefore not surprising that both methadone and buprenorphine are on the World Health Organization's list of essential drugs. ${ }^{23}$

\section{OST options}

\section{Methadone}

The introduction of methadone in the 1960s revolutionised the medical treatment of opioid dependence. Dole and Nyswanger and colleagues showed that heroin-dependent patients maintained 
on methadone could give up the drug and lead productive and law-abiding lives. ${ }^{24}$

Methadone substitution treatment not only prevents withdrawal symptoms but if given in high enough doses causes crosstolerance, thereby blocking the euphoric effects of abused opioids such as heroin.

Methadone is a full mu opioid agonist, and the biggest concern with its use is that of toxicity. It can cause serious motor function impairment and potentially fatal respiratory depression. High-dose methadone is also associated with a risk of QTc prolongation and torsades de pointes. ${ }^{25}$ Furthermore, it is liable to black-market diversion, and in view of this and the high risk for toxicity, many countries have enforced strict regulations with regard to methadone substitution treatment, including rigorous control measures such as daily supervised consumption by specialised clinics.

Until recently methadone was only available in South Africa as a cough syrup, unsuitable for OST, but a suitable formulation has recently been registered for this purpose.

\section{Buprenorphine}

Buprenorphine is a long-acting sublingual partial opioid agonist with low intrinsic activity and high receptor affinity, and the added benefit of a ceiling effect (a maximum level of pharmacological action with flattening of the dose-response curve). ${ }^{26}$

One of the biggest concerns with black-market diversion of substitution opioids is the risk of serious toxicity and death, especially if they are ingested by non-tolerant individuals such as children. The maximum effect that buprenorphine can produce is lower than that of a full agonist, and this ceiling effect results in a significantly lower risk for toxicity, even for non-tolerant individuals, thus reducing overdose risk and making it more useful for office-based practice. It binds tightly to receptors and is difficult to displace, further improving its safety profile if a full agonist, such as heroin, is used 'on top'. There have been rare reports of overdose deaths, usually when oral formulations were used intravenously and with other depressant substances such as benzodiazepines. ${ }^{27}$

\section{Buprenorphine-naloxone combination}

Initial reports suggested that buprenorphine would have low abuse potential. ${ }^{28}$ However, parenteral abuse and black-market diversion have been reported worldwide. ${ }^{29}$ Tablets are crushed and diluted and then administered intravenously. Strategies to prevent injection use of buprenorphine have therefore been developed in the form of a buprenorphine-naloxone combination tablet.

Naloxone has low sublingual absorption, whereas buprenorphine has reasonably good absorption sublingually. If naloxone is administered parenterally to an opiate-dependent individual, rapid and unpleasant withdrawal symptoms ensue. The combination tablet is therefore an effective deterrent to injection use. Studies have shown that a $4: 1$ ratio of buprenorphine/naloxone is able to precipitate a highly unpleasant but relatively safe withdrawal if given intravenously, but is as effective in preventing withdrawal as sublingual buprenorpine alone. ${ }^{30}$ Buprenorphine-naloxone therefore allows less tight supervision of consumption and earlier take-home medication. This translates into significantly cheaper treatment. ${ }^{31}$

Buprenorphine-naloxone has recently been launched in South Africa and provides a safe firstline office-based treatment option for OST.

\section{Can we afford not to provide the best possible treatment?}

There have been at least three influential longitudinal studies looking at treatment outcome in heroin dependence, namely the Drug Abuse Treatment Outcome Study (DATOS, USA), ${ }^{32}$ the National Treatment Outcome Research Study (NTORS, UK) ${ }^{33}$ and the Australian Treatment Outcome Study (ATOS). ${ }^{34}$ These studies confirm that treatment is effective across a wide range of outcomes, including reduced drug use and crime, as well improved physical and mental health. OST is viewed as a costeffective intervention, and it is estimated that for every dollar invested, treatment will yield a $\$ 4$ - 7 return in crime reduction, criminal justice cost and theft alone. This may exceed 12:1 if health care is included. ${ }^{8}$

\section{What can we learn from international experience?}

Highly regulated systems are safe, like the Australian model, where doctors are required to undergo mandatory training and registration in order to prescribe OST, individual patient permits are issued, and strict guidelines, including rigid supervised consumption, apply. Highly regulated systems are associated with low rates of diversion, intravenous use or deaths due to prescribed medication and provide comprehensive packages of care to patients, but are costly and therefore tend to offer only limited treatment spaces. This implies limited public health 
impact. Furthermore, these highly controlled services are often not agreeable to patients, who find daily supervised dosing extremely tedious.

Minimally regulated systems, used in countries such as Malaysia, Singapore and France, have the advantage of rapid and wide roll-out and are therefore able to make a big public health impact, including reductions in opioid death rates, HIV transmission, crime and prostitution, and improved employment and social functioning. ${ }^{35}$ The downside seems to be high rates of injection use of prescribed medication labout $20-30 \%$ in France), diversion, other problems due to lack of training, such as co-morbid benzodiazepine prescribing lup to 50\% of French patients on buprenorphine), and no psychosocial interventions.

The UK and the USA have both introduced moderately regulated systems. In the UK, OST has been provided through shared care by an enhanced primary care service supported by specialist services. General practitioners receive training and guidelines, and funding is linked to targets. Methadone is widely used and a well-developed supervised dispensing system is in place. This system is, however, extremely costly.

The USA has 40 years of experience with highly regulated methadone clinics, but without broad access to these clinics. Learning from the French experience, they delayed the rollout out of buprenorphine into office-based primary care until buprenorphine/naloxone became available, and this is now mostly provided with little or no supervised dosing. There are some regulatory controls, e.g. a capped number of patients per clinician, doctor training and registration and treatment guidelines, and this approach has led to a largely expanded treatment provision system. ${ }^{35}$

\section{The way forward for South Africa}

It is clear that if we are to successfully treat this complex and treatment-resistant disorder, thereby reducing associated health and social problems, we need to implement a range of treatment options. Discussions around the provision of OST in the state sector have been a political hot potato, however, and no final decision regarding the provision of this internationally accepted and minimum standard treatment approach has been made. This is of concern in view of growing use of injection drugs and the high risk of HIV and hepatitis $C$ transmission among users. The progressive increase in the number of heroin-using patients indicates that we need to prepare ourselves for a possible heroin epidemic. Some might even argue that heroin dependence has already reached epidemic proportions in some areas. We need to consider the growing extent of our local problem, its impact on health and society, the availability of local resources, the efficacy of our current treatment system, and political conditions and attitudes, to name just a few.

It may be safest to introduce OST as an alternative to abstinencedriven treatment via a limited and regulated 'clinic' system in order to establish goodwill and develop a skilled workforce with local expertise. Once expertise is established, however, we should aim to widely roll out OST programmes in order to have a significant public health impact. If we want to truly 'defeat the dragon', we will need wide political buy-in and support.

Thanks to Dr Mimi Roberts and Dr Srnka Flegar for help with editing

Declaration of interest. Sponsorships and honoraria have been received from Shering Plough, Equity pharmaceuticals and Reckitt Benckiser.

\section{Lize Weich}

Department of Psychiatry

Stellenbosch University

1. Kosten TR, George TP. The neurobiology of opioid dependence: implications for treatment. Sci Pract Perspect 2002; 1 (1):13-20.

2. United Nations Office for Drugs and Crime. 2007 World Drug Report. http://www. unodc.org/unodc/en/data-and-analysis/WDR-2007.html laccessed 14 September 2010).

3. Plüddemann A, Dada S, Parry C, et al. Monitoring alcohol \& drug abuse trends in southern Africa Uuly 1996 - June 2009). Phase 26 SACENDU research brief 2009; 12(2). http://www.sahealthinfo.org/admodule/sacendu.htm (accessed 14 September 2010)

4. Plüddemann A, Parry C, Jordaan E, Flisher A. The nature and extent of heroin use in Cape Town. hitp://www.sahealthinfo.org/admodule/reportheroinphase2.pdf laccessed 14 September 2010).

5. Plüddemann A, Pary C, Flisher A, Jordaan E. Heroin users in Cape Town, South Africa: injection practices, HIV-related risk behaviors and other health consequences. J Psychoactive Drugs 2008;40(3):273-279

6. Rounsaville B, Weissman M, Kleber $\mathrm{H}$, Wilber $\mathrm{C}$. Hetrogeity of psychiatric diagnosis in treated opiate addicts. Arch Gen Psychiatry 1982;39:161-166.

7. Hulse $G$, English $D$, Milne $E$, Holman $C$. The quantification of mortality resulting from illicit opiates. Addiction 1999:94:221-229.

8. WHO/UNODC/UNAIDS position paper. Substitution maintenance therapy in the management of opioid dependence and HIV/AIDS prevention. http://www.unodc. org/docs/treatment/Brochure_E.pdf (accessed 14 September 2010).

9. Gossop M, Stewart D, Browne N, Marsden J. Factors associated with abstinence, lapse or relapse to heroin use after residential treatment: protective effect of coping responses. Addiction 2002; 97: 1259-1267.

10. Price RK, Risk NK, Spitznagel EL. Remission from drug abuse over a 25-year period: Patterns of remission and treatment use. Am J Public Health 2001;91:1 107-1 113.

11. Weich L, Perkel C, Van Zyl N, Rataemane ST, Naidoo L. Medical management of opioid dependence in South Africa. S Afr Med J 2008;98(4):280-283

12. Minozzi S, Amato L, Vechi S, Davoli M, Kirchmayer U, Verster A. Oral naltrexone maintenance treatment for opioid dependence. Cochrane Database Syst Rev 2006 Jan 25: (1) CD 001333

13. Gossop M, Marsden J, Stewart D, Lehmann P, Strang J. Methadone treatment practices and outcome for opiate addicts treated in drug clinics and in general practice: results from the National Treatment Outcome Research Study. Br I Gen Pract 1999:49:31-34

14. Strain EC, Stitzer ML, Liebson IA, Bigelow GE. Dose-response effects of methadone in the treatment of opioid dependence. Ann Intern Med 1993; 1 19:23-27.

15. Bates $M$, Pemberton DA. The effects of methadone prescribing in a clinic setting on the criminal activity of drug users. Scott Med J 1996;41:173-175.

16. Strain EC, Stitzer ML, Liebson IA, Bigelow GE. Buprenorphine versus methadone in the treatment of opioid dependence: self-reports, urinalysis, and addiction severity index. J Clin Psychopharmacol 1996;16:58-67. 
17. Gunne LM, Gronbladh L. The Swedish methadone maintenance program: a controlled study. Drug Alcohol Depend 1981;7:249-256.

18. Ball JC, Lange WR, Myers CP, Friedman SR. Reducing the risk of AIDS throug methadone maintenance treatment. J Health Soc Behav 1988;30:673-684

19. Dole VP, Joseph $\mathrm{H}$. Long-term outcome of patients treated with methadone maintenance. Ann NY Acad Sci 1978;31 1:181-189.

20. Fairbank JA, Dunteman GH, Condelli WS. Do methadone patients substitute other drugs for heroin? Predicting substance use at 1-year follow-up. Am J Drug Alcohol Abuse 1993:19:465-474

21. Caplehorn JR Dalton MS, Cluff MC, Petrenas AM. Retention in methadone maintenance and heroin addicts' risk of death. Addiction 1994;89:203-209.

22. Sees, KL Delucchi KL, Masson C, et al. Methadone maintenance vs. 180 day psychosocially enriched detoxification for the treatment of opioid dependence: a randomized controlled trial. JAMA 2000;283:1303-1310.

23. Herget, $G$. Methadone and buprenorphine added to the $\mathrm{WHO}$ list of essential medications. HIV AIDS Policy Law Rev 205; 10:23-24

24. Dole VP, Nyswander M. A medical treatment for diacetylmorphine (heroin) addiction. A clinical trial with methadone hydrochloride. JAMA 1965: 193:646-650.

25. Krantz MJ, Mehler PS. QT Prolongation: methadone's efficacy-safety paradox. Lance 2006; 368:556-557.

26. Dumm JE. Herz A. In vivo receptor binding of the opiate partial agonist, buprenorphine, correlated with its agonist and antagonist actions. Br J Pharmacol $1981 ; 74: 627-633$
27. Reynaud M, Tracqui A, Petit G, Potard D, Courty P. Six deaths linked to misuse of buprenorphine-benzodiazepine combinations. Am 」 Psychiatry 1998:155:448-449.

28. Jasinski DR, Pevnick JS, Griffith JD. Human pharmacology and abuse potential of the analgesic buprenorphine. Arch Gen Psychiatry 1978;35:50 1-516.

29. O'Connor $ل$, Moloney E, Travis R, Cambell A. Buprenorphine abuse among opiate addicts. Br J Addict 1988;83:1085-1087.

30. Mendelson J, Jones RJ, Clinical and pharmacological evaluation of buprenporphine and naloxone combinations: why the 4:1 ratio for treatment? Drug and Alcohol Dependence 2003:70:529-S37.

31. Bell J, Shanahan M, Mutch C, et al. A randomised trial of effectiveness and costeffectiveness of observed versus unobserved administration of buprenorhine-naloxone for heroin dependence. Addiction 2007; 102:1899-1907.

32. Simpson DD, Joe GW, Brown BS. Treatment retention and follow-up outcomes in Drug Abuse Treatment Outcome Study (DATOS). Psychol Addict Behav 1997;1 1:294 307

33. Gossop M, Marsden J, Stewart D, Kidd T. The National Treatment Outcome Research Study (NTORS): 4-5 years follow-up results. Addiction 2003;98:291-303.

34. Teeson M, Mills K, Ross J, Darke S, Williamson A, Harvard A. The impact of treatment on 3 years' outcome for heroin dependence: findings from the Australian Treatment Outcome Study (ATOS). Addiction 2008; 103:80-88

35. Lintzeris N. Maximising access: a tale of morality, politics and pharmacology. Presented at the Improving Outcomes in the Treatment of Opioid Dependence conference, 21 - 23 April 2009, Cannes, France. 